\title{
ORAL RHETORIC IN WRITINGS FOR A MIXED LITERATE AND ILLITERATE AUDIENCE
}

\author{
Ulrich $\mathrm{BACH} *$
}

The main point of this paper is the transfer made by 17 th century pamphleteers of the oral rhetorical strategy of artificial memory to written to-be-read-aloud texts in order to facilitate comprehension and retention of their contents by listeners. This new function of an oral strategy is discussed against the general background of the relationship between orality and literacy within the domain of early printed mass-communication. It is argued that the role of oral strategies in serving the needs of mixed literate and illiterate audiences during the long-term transition from orality to literacy is more complex than the traditionally held view of orality as the opposite of literacy might suggest.

\section{Introduction}

A basic question in pragmatically and historically oriented textual studies is that of the nature of the interaction between oral and literate strategies within the various domains of verbal communication during the long-term transition from orality to literacy in European societies after the advent of printing, as more social groups were brought into contact with written texts in the process. The relevance of this question rests on the assumption that it would be too simple to view the diachronic relationship between orality and literacy as that of a constantly rising and strictly uni-directional development towards the latter.

The advantage of the analysis of discourse occurrences in historical contexts is that these offer conditions of verbal communication such as situations of reading aloud printed texts to an illiterate audience which are no longer common today. The political and educational factors active in the larger historical context of mid-seventeenth century England, for instance, account for a marked mixing of orality and literacy within the domain of printed mass-communication through broadsides and pamphlets, exhibiting evidence for the role of oral rhetorical strategies in the process of establishing this domain.

* I am grateful to the anonymous reviewers of Poetics for some interesting suggestions which I freely made use of in the final version of this paper.

Author's address: U. Bach, Helmholtzstrasse 8, D-4040 Neuss 1, FRG. 
As an example, we want to demonstrate the transfer made by pamphleteers of an oral rhetorical strategy to the organization of persuasive writings intended for a mixed literate and illiterate mass audience in the particular situation of communication at the beginning of the English Civil War in 1641. It is our thesis that this transfer primarily served the goal of enhancing the effect of oral transmissions of pamphlets and broadsides by facilitating the comprehension and retention of their contents under the specific conditions of a listening situation. The particular conditions of the communicative background (as far as they can be reconstructed) are taken into account in explaining that transfer.

The analysis of historical events of communication, however, is subject to certain restrictions: We cannot reconstruct individual historical processing activities, neither can we prove that a text was consciously designed with a certain cognitive function in mind. This leaves us only the possibility to identify and describe textual elements of undisputably oral rhetorical origin, to explain them by relating their occurrence to the historical situation of communication and check, in the light of our present-day knowledge of discourse processing strategies, their potential to guide and facilitate the comprehension and retention of textual material by a listening audience in triggering strategies which are actually employed by language users.

\section{The historical and educational context of 17th century printed mass-communication in England}

The sudden and stupendous rise of printed mass-communication through broadsides and pamphlets in England following the collapse of the royal control of the press in 1641 led to a rise in reading-aloud and talking-about situations, i.e. a rise in the overall number of oral communicative events (or oral transmissions of texts): It is a well-known fact that printed pamphlets were read out to illiterate (and also to literate) listeners in the street, from the pulpit and in private (Hill (1982: 103f.), Shepard (1973: 14, 21), Wedgwood (1983: 49)). There are two main reasons for this seeming paradox: Firstly and principally these texts, as a means of mass-communication, aimed at reaching effectively as many individuals as possible, pamphlets being in the words of the contemporary Sir Leoline Jenkins, Secretary of State from 1680-1684, 'a sort of appeal to the people' (quoted after Traue (1978: 108)). Secondly, the England of the mid-seventeenth century was still a predominantly orally communicating society. The traditional assumption that literacy was constantly rising between 1530 and 1730 has recently been called into question (Cressy (1980), O'Day (1982)); thus, the 'educational revolution' (Stone (1964)) in England from the end of the 16th to the middle of the seventeenth century had not produced a literate society, but 'a hierarchy of illiteracy which 
faithfully mirrored the hierarchy of status and wealth' (Wrightson (1984: 190)). Even for London, the average male literacy rate in the mid-seventeenth century is estimated at no more than $60 \%$, varying for the rest of the country from $15 \%$ to $40 \%$ (Stone (1969: 101)).

While the reading aloud of written texts had been a customary feature of literary communication among the educated higher classes in the Middle Ages (Bergner (1988), Ong (1982), Bäuml (1980)), this practice (only) now began to extend to the non-literary, politico-religious topics 'of the day' and to social classes which had hitherto not been accustomed to having printed texts read to them. In judging this development we have to consider the fact that discussing and publishing matters of public concern was principally forbidden and heavily punished as an intrusion upon the royal prerogative at the time under consideration (Siebert (1965)).

To sum up: The historical situation within the domain of mass communication is characterized by the practice of reading out printed pamphlets to others, thereby retaining a strong element of orality in printed mass-communication with two important consequences for the illiterate listener: He had to process (with little or no experience) discourse in the written variety of his language, and he had to do this under the conditions of the ephemeral oral communication.

In oral situations of communication the capacity limits of human memory make themselves quickly felt in comprehending and remembering texts. Listening makes specific demands on the comprehender's memory in that the listener does not have the reader's means of pausing, turning back a page and re-reading an earlier word, sentence, or passage at will to help comprehend, retain and remember a text. This essential difference between listening and reading is partly made up for in spoken discourse by the use of medium-specific language features often described loosely as 'oral style': by various means, a speaker may adjust his discourse to the listener, the medium and the communication situation (see, for instance, Chafe $(1976,1982)$, Akinnaso (1982, 1985)).

It directly follows that in the case of medium transfer like that of printed pamphlets being read aloud for a listening audience, the demands made on the listener's capacity for comprehension and retention may be considerably higher still, depending on the degree to which a text's syntax, semantics and global structure conform to the conventions of written discourse. (The same holds for the opposite case of medium transfer: readers of word-by-word protocols of spontaneous conversation will be familiar with the particular difficulties.)

It seems important, then, to analyze those printed pamphlets with respect to the means and strategies by which the writers assured easy comprehension and retention. The central role of comprehensibility in mass-communication is undisputed (cf. e.g. Koscyk (1974)). 
The further claim that the writers also aimed for memorability calls for a specific explanation. Given the primary objective of mass-communication to reach as many people as possible, it is reasonable to hypothesize that the pamphleteers recognized the importance for people to talk about the contents of the pamphlets to others in order to multiply their impact. To do so effectively entailed making comprehension and retention easy. Furthermore, in addition to their general functions of persuading and attacking, many of the pamphlets exhibit a distinctly instructional intention. The instructional intention is closely connected with the immediate political background of religious strife and civil war, where the public had to be instructed on major and minor points of theological tenets. Moreover, it has to be seen against the wider Protestant background of a marked emphasis on teaching and on catechisms serving the instruction of believers down to the tiniest village community and also of the outspoken iconoclasm of radical Calvinist Puritans, which favored the authority of the written (and spoken) word. The instructional aspect and the concomitant need for retention-supporting means is most clearly visible in the case of list-type pamphlets.

Lists are no rare occurrence among the broadsides and pamphlets of the Civil War Epoch. In the largest (but by no means complete) contemporary collection of pamphlets and broadsides from the years 1640-1661, the Thomason Tracts (British Library, London and on microfilm 1981) we find lists of the following kinds of items:

victories

castles and towns taken

casualties and prisoners of war

ships and their captains

the gentry and the nobility

men to be raised for service

judges of courts

members of Parliament

participants in processions

sects and their tenets

books

sermons preached before the Commons

cruelties and sins attributed to opponents

queries of Parliament

prices for the bindings of books of various sorts

arguments of religious and political controversy

founders and benefactors of the Universities

habits and gestures despised as 'apish'

superstitious objects and ceremonies

patentees of the wine trade and of other trades

hard words 
The confusing multitude of, for instance, rivalling sects and their tenets, of prominent figures fallen into disgrace, or of military events seemed to ask for a list-like registration and overview. Moreover, the material contained in list-type pamphlets and broadsides could often prove to be of vital importance for the individual listener, given the historical situation of civil war, religious intolerance and witchcraze: e.g. lists of casualties and prisoners of war or lists of sects and their tenets, but still more so lists of those religious symbols, rites and things which, while banned as the signs of evil superstition, were nevertheless to be made known and learned for the public to avoid such superstitious behaviour and denounce it in others.

Pamphlets in the form of a list, it becomes clear, often served a second, less evident purpose besides being polemical and mocking attacks, or persuasive tracts on the issues of the day. Many of them are also and primarily, as we believe, meant as an instruction of the masses on such often complex issues as religious beliefs and forms of behaviour.

Any instructional intention is necessarily connected with the concepts of comprehension, retention and remembering; comprehension in the first place is not possible without the capability of keeping in memory the words heard (or read) immediately before those which are currently being processed. Without this capability, there is no coherent representation of a text's semantic structure possible and a true integration into the already stored knowledge of the comprehender fails (Van Dijk (1980: 165)).

In addition, the specific problem for listeners to comprehend and - above all - retain and remember a written text in the case of medium transfer (discussed above) becomes more pertinent in the case of lists. For lists, indexes, and similar enumerating texts are basically texts for reading and writing (Ong (1982), Goody (1977)). They are considered as a genuine child of literacy; oral cultures, it is maintained, have no lists, tables or diagrams.

The linguistic properties of lists confirm this view. Lists as a type of text in their own right have only little cognitive structuring and substantially reduced coherence, being often no more than a simple sequence of separate items (of varying complexity) whose common class-membership is explicitly stated only once, in the title of the list. Therefore the list comprehender has little to go by in the form of helpful signals for reconstructing the list in his mind or for memorizing single items. Those signals of cognitive structuring which written lists typically possess (e.g. alphabetical, numerical, or chronological order, or typographical cues like indention and hyphens) are more directly related to the printed medium in that they provide a means to refer to and find quickly specific items in identical copies of a text (cf. Eisenstein (1979: 88ff.), Ong (1958, 1967a, b, 1971, 1982)).

Lack of structure and of coherence make heavy demands on the capacity for retention, and hence comprehension, on the part of the listener (Kintsch and Van Dijk (1978), Kintsch (1979), Van Dijk (1980), Van Dijk and Kintsch 
(1983), Ballstaedt et al. (1981)). He will therefore have to look out for additional cues or, lacking these, employ inferencing strategies which help to generate coherence and global structures and which make the integration of textual information into the already stored knowledge easier. It is the additional cues in a list-type pamphlet that we shall now turn to.

\section{Analysis of the transfer of the oral rhetorical strategy of mental imagery to a written text}

A True Inventory of the Goods and Chattels of Superstition, Late of the Parish of Ignorance, in the County of Blind-Devotion, and in the Kingdome of Idolatry, deceased: Taken and apprised, this nineteenth of February Anno Domini 1642, London 1642 (Thomason Tracts, E.135.3.)

This is the title of a four-page pamphlet. When studied under the pragmatic and cognitive aspect of text comprehension in an oral situation of communication, this pamphlet reveals the cognitive function of the transfer of an oral rhetorical device which is used as a kind of visual 'clothing' of the text's underlying list structure.

This mock-inventory enumerates the typical symbols, rites and objects of 'idolatrous' or 'superstitious' worship, stock arguments of the Puritans' fight against the 'popish' church innovations which had been introduced by Archbishop William Laud, and imitates the conventional text-type of inventory. It follows the formal principle of a list. From a speech-act perspective, its specific purpose is at least a double one (beyond the general purposes of pamphlets and broadsides to persuade and/or amuse their audience): that of a satirical Puritan attack against 'superstition', its followers and the authority behind them and, less ostentatiously, that of an instruction on the signs of superstition. Taking the more evident purpose of a satirical attack on 'popish' beliefs and behaviour first, we note that the imitated text-type of (mock) inventory serves as a vehicle for the satirical purpose, which signals that the 'superstitious' religion is already dead and overcome (presupposing the reader's/listener's pragmatic knowledge that inventories are made only after the testator's death) and which also characterizes this religion by the nature of its possessions.

But primarily, as we have argued above, this list-text serves as an instruction of the masses on the signs of superstition. This view of an instructional intention behind the text's publication is supported by its intertextual relations: there is a great number of similar texts by other Puritan authors, not to forget repeated orders by the authority, 'to be read in every church', to remove all superstitious objects from the churches and to abolish all such forms of behaviour in worship: An Order of the Commons of 8th September 1641 
(Thomason Tracts, 669.f.3.14.), Order from the House of Commons for the abolishing of Superstition and Innovation in Church affaires, 1641 (Thomason Tracts, E.171.8.), Foure Orders Of great Consequence, 1641 (Thomason Tracts, E.102.5.). With the text seen as an instruction, then, and taking into account the cognitive demands of the oral transmission of printed texts, the choice of the text-type inventory as a 'clothing' of the list of superstitious items has to be judged in a light different from that of a mere stylistic function as a vehicle for satire. The particular structural features of the text-type 'inventory' are made to serve a second, cognitive function, which is directly related to the instructional intention and the historical situational context of communication. What textual elements are there to substantiate this claim? By representing the items as chattels in a household and by listing them in the manner of an inventory:

In the Parlour.

Item, two Images of the Virgin Mary, and of Christ her

Sonne. 20.li.

Item, behind the Hangings in this Parlour, Images of most of the Popes [...]

(p. 1)

the comprehender's cultural knowledge of houses and their interiors, but also of furniture, their use and their relation to different kinds of rooms becomes relevant as prior knowledge. There is no explicit explanation of what a house and its parts are; instead, the referents are introduced with the definite article, thereby treating them as generally known and universal objects of houses: 'In the Parlour', 'in the Hall' etc.

We might object that not everybody could have had personal knowledge of a house of the formal type which is presupposed by such rooms as great chamber, library, or chapel of ease (see below). Yet from 17th century formal houses like Coleshill House or Ragley Hall and from plans by the architect $\mathrm{J}$. Thorpe it becomes clear that it is only the public section of a formal house, its 'central axis' (Girouard (1980: 119ff.)), which is made use of; rooms which in the 17 th century were peripheral and reserved for the family are not mentioned. Moreover, the relative locations of rooms are made linguistically explicit, thus counterbalancing individual differences in the knowledge of houses among the anonymous mass-audience.

If we disregard the listed 'household' items, and isolate from $A$ True Inventory the expressions referring to the house and the relative locations of the rooms:

In the Hall $[\ldots]$

In the Parlour $[. .$.

Behind the Hangings in this Parlour $[\ldots]$ 
In the Chamber over the Hall [...]

In the Chamber over the Parlour [...]

In the Library or study in this Chamber [...]

In the Chappell of Ease adjoyning to the House [...]

In the Vestry [...]

(pp. 1-3)

it becomes clear that they order a succession of items on the basis of the generally familiar knowledge schema 'HOUSE' including its basic or typical architecture. Conversely, viewed without these signals, the bare items of the list form a largely unstructured succession which, when read aloud, is difficult to retain and to remember even in parts:

pictures of his Holinesse the Pope Pius 5.

of the Virgin Mary

of Saint Peter

and the rest of the Apostles

pictures of divers Saints departed

holy Fathers, Patriarchs, Cardinalls, Bishops, Priests,

Jesuites, and Friars

pictures of crosses

Images of the Virgin Mary, and of Christ her Sonne

Images of most of the Popes

holy-Bread, holy-Water, and fragments of their Eucharist

Prayer-books to Saints

pretious stones and jewels, sent as tokens from his Holinesse

Reliquies of Saints

a Book of Apocrypha

a Book of Ave Maries, all which are in the Latine tongue

Tombs of Saints, with the images of them intombed

Copes, Hoods, lawn sleeves, Surplices

Bowing, creeping, crawling, bowing to the East

Wax-candles, Dirges, Beads, Red crosses

Signing with the Crosse [...]

(pp. 1-3)

Apart from rudimentary formal structuring by attempts at the church hierarchy (holy Fathers, Patriarchs, Cardinals, Bishops, Priests), it is only the strategy of multiple repetition of some of the items (notably the images of saints) which may be interpreted as a structural pattern with a positive effect on the retention of these items.

By ordering the list of items on the basis of the typical structure of a house (hall, parlour, chamber over the hall, chamber over the parlour...), the writer superimposes a structural net on the list of items. The contents of the text, the informational gist, is tied to something which to a certain extent the compre- 
hender already knows, which therefore he doesn't have to learn the way he has to learn the 'information', i.e. the individual items of superstition. Instead, he can profitably use this prior knowledge when trying to keep the items in mind and remember them.

Moreover, from a cognitive point of view the spatial expressions such as 'behind the Hangings in this Parlour', 'in the Chamber over the Hall' in toto enhance the formation of the mental image of a house or rather a series of mental images which, being in a fixed and familiar order, induce the comprehender to make a mental walk or 'tour' through that house in close correspondence with his prior general knowledge of houses: for instance, that the first room of a house you enter is the hall and that the 'chamber' is a room on the first floor, parlours being typically on the ground floor. That this strategy seems to have psychological reality, is shown by an experiment by Linde and Labov (1975). They have found in an experiment that the mental walk ('tour') was significantly preferred by speakers over other possibilities of verbally describing spatial patterns and lay-outs of apartments to listeners.

What the comprehender still has to do in remembering the list is to fill the house with the objects or items the particular list contains. This visualization of items is made easy by their representation as bits of furniture or as attached to furniture. We note further that the items are placed in typical or conventional places in rooms which are appropriate for such items:

In the Chappell of Ease adjoyning to the House.

[...] Item, Tombs of Saints, with the images of them intombed.

(p. 3)

In the Parlour.

[...] Item, a rich enameled close Cup-boord, wherein is kept holy-

Bread, holy-Water, and fragments of their Eucharist. 30.li.

(p. 1)

As we can see, not all of the 'furniture' mentioned is really meant as items of the list of superstitions (the cupboard merely contains the 'superstitious' items of holy bread etc.), but serve instead as an item's visual repository or carrier notably in cases where the item meant is abstract:

Item, a paire of Andirons guilded, wherein is engraven the images of his Holinesse the Pope and S. Peter $20 l i$. (p. 2)

Item, in the Library or study in this Chamber, a Book [...], a Book $[\ldots]$; all of which are in the Latine tongue (p. 2)

Neither the andirons nor the books in these examples are meant to be learnt and remembered as superstitious items. In the first case, the images of holy 
people stand for the abstract concept of idolatry, and in the second case the books convey the abstract concept of the use of Latin (within the domain of worship).

The association of a repository and an item and of a repository and its place within the structure of the house again is guided by the principles of familiarity and typicalness: 'Holy bread' is put in the easily associated cupboard, and the cupboard is placed in the parlour (instead of the hall, the chamber or the chapel). Idolatry is associated first with engravings and via these with the familiar object of a pair of (decorated) andirons, which in turn can be readily visualized in their conventional place (in front of the fire-place) in a certain first-floor room (a 'chamber'), this being easily localized on the basis of the familiar structure of a 17th century house ('in the Chamber over the Hall'), over the room of entry, that is, and to be reached via it. The use of Latin, finally, is associated easily with the concrete image of 'books', which are set in a typical place, the library, which is part of a particular first-floor room (a chamber) which in turn is located over the parlour within the overall structure of the house ('in the Chamber over the Parlour'), the parlour being also reached via the hall.

By this strategy, the recoverability of items, their retention and remembering, is facilitated: By following the conventional order of rooms in the house (supported by the general knowledge of houses) it is made easy for the comprehender in many cases to infer or 'reclaim' the item meant from its associated repository with the help of his knowledge of the world and to remember it subsequently from the latter's place within the architecture of the house.

Both, the mental walk through the house, and the visualization of items as attached to pieces of furniture in their typical places within the structure of the house help to 'find again' the particular items of the list and even to remember substantial parts of it if not the whole list, serving as a kind of artificial memory.

\section{Explanation}

By 'artificial memory' we refer to rhetorical strategies which had been developed in classical times to overcome the boundaries set to natural (innate) memory by improving its efficiency and which, as ars memoria, form the fourth part of traditional rhetoric besides inventio, dispositio, elaboratio, and pronuntiatio of the matter of speech (see Yates (1966)). Associating items with familiar objects, visualizing these in their traditional or typical places and ordering these places corresponding to a well-known global structure is nothing else than the classical imagines-and-loci-method of the ars memoria, as it had been described by Cicero and other classical rhetoricians and as it 
was explained again in the age of print in England by Bacon in his Novum Organum. All these texts quote as an example of a known-in-advance global structure some well-known building like a house, a temple, or a theatre to help order and remember the items. The experiment by Linde and Labov (1975) mentioned above has shown that the particular device of a 'tour' has some degree of psychological reality. Furthermore, spatial representation of a text's contents (as opposed to a purely propositional representation) may have a beneficial effect on memory for prose (Wagener and Wender (1985)). Finally, the effectiveness of the classical imagines-and-loci-method as a mnemonic aid has repeatedly been demonstrated (Higbee (1979), Hoffman (1980), Bellezza (1981), Maher and Sullivan (1982)) and its working explained in terms of modern cognitive psychology (Neisser (1976: 137f.); for a discussion of the use of imagery in text comprehension, see also Miller $(1979)$, Paivio $(1979,1986))$.

But there is one important difference between the rhetorical device and its use in this 17th century printed pamphlet taken from the domain of masscommunication. In rhetoric, it was a production-oriented means to help the individual speaker remember the particulars of his text for uttering, but here it is converted to or re-defined as a comprehension-oriented help for the anonymous listeners to an orally presented written text to remember the important particulars for his own benefit and also for talking about them to others. This significant change of application from that of a single speaker to that of a potentially large and mixed group of listeners shows in the fact that the relative locations of the room in $A$ True Inventory are made linguistically explicit, thus anticipating individual differences in experience and consequently knowledge of houses.

It is a standard argument in discussing the role of artificial memory in the diachronic relationship of orality vs. literacy that the method of loci-andimagines was designed to make oral prose memorable and that therefore it became redundant once texts were fixed by writing, for writing removed the need for prose to be memorable - you can always look it up again (Olson (1988)). Our findings do not confirm this view. The author-strategy of verbally 'clothing' a printed list by means of mental imagery (to make the text memorable in the likely event of its being read out to a listening audience) testifies to the fact that the oral technique of artificial memory was put to a new use in the written medium.

The list-processing strategy of visualization analyzed here is based on an example of the utilization of the house-image. Within the same historical context of mass-communication there are other examples of secondary verbal 'clothing' by superimposed structures of list-type pamphlets which make use of such divergent yet familiar cultural knowledge units as that of a fair: Lambeth Faire, Wherein you have all the Bishops Trinkets set to Sale (1641, Thomason Tracts, E.158.20.), of a funeral procession: The Remarkable Funeral of Cheapside-Crosse (1642, Thomason Tracts, E. 132.38.), and of a pack of 
cards: A Pack of Patentees. Opened. Cvt. Dealt. And Played (1641), Thomason Tracts, E. 163.5.).

\section{Conclusion}

The analysis has demonstrated the transfer of an oral rhetorical device to writings for a mixed literate and illiterate audience. This example of a redefined use of the oral technique of artificial memory is evidence for the complex and ambiguous nature of the relationship between orality and literacy in the process of the general transition from orality towards literacy in many domains of verbal communication. As assessment of the full role which oral rhetoric played within the domain of early printed mass-communication necessitates full-length studies which have to be based on the truly immense corpus of 17th century English broadsides and pamphlets so surprisingly neglected by text linguists.

The transfer of the classical rhetorical device to a new use in this 17th century printed text taken from the domain of mass-communication also sheds some light on the general history of the cross-relationship between orality and the expansion of literacy. Early mass-communication, it seems, acts as a catalyst: Print, itself a salient manifestation of literacy, made possible the reading out of written news quickly, cheaply, in identical form and simultaneously in many places, whereas the oral technique of artificial memory became subservient to printed discourse in facilitating its comprehension and retention by listeners. Thus, literacy was quick enough to avail itself of the means of orality in a specific historical and educational context and situation of communication. Orality, on the other hand, by playing an active and necessary part in helping printed mass-communication to reach the masses and to spread the written standard in the form of public readings, proved resourceful enough to adapt itself to new needs and thus to 'linger on' in a new medium. Reading out printed texts to others had the general effect of carrying along orality into printed mass-communication.

\section{References}

Akinnaso, F.N., 1982. On the differences between spoken and written language. Language and Speech 25: 97-125.

Akinnaso, F.N., 1985. On the similarities between spoken and written language. Language and Speech 28: 323-359.

Ballstaedt, S.-P., et al., 1981. Texte verstehen, Texte gestalten. München: Urban \& Schwarzenberg. Bäuml, F.H., 1980. Varieties and consequences of medieval literacy and illiteracy. Speculum 55: $237-265$. 
Bellezza, F.S., 1981. Mnemonic devices: Classification, characteristics, and criteria. Review of Educational Research 51: 147-275.

Bergner, H., 1988. Das mittelenglische 'mystery play': Mündliche, bildliche und schriftliche Kommunikation. In: W. Erzgrüber and S. Volk (eds.), Mündlichkeit und Schriftlichkeit im englischen Mittelalter, 165-183. Tübingen: Narr.

Chafe, W.L., 1977. Creativity in verbalization and its implication for the nature of stored knowledge. In: R.O. Freedle (ed.), Discourse production and comprehension. Norwood, NJ: Ablex.

Chafe, W.L., 1982. Integration and involvement in speaking, writing, and oral literature. In: D. Tannen (ed.), Spoken and written language: Exploring orality and literacy, 35-53. Norwood, NJ: Ablex.

Cressy, D., 1980. Literacy and the social order. Cambridge: Cambridge University Press.

Eisenstein, E., 1979. The printing press as an agent of change. Cambridge: Cambridge University Press.

Girouard, M., 1980. Life in the English country house: A social and architectural history. Harmondsworth: Penguin.

Goody, J., 1977. The domestication of the savage mind. Cambridge: Cambridge University Press.

Highbee, K.L., 1979. Recent research on visual mnemonics: Historical roots and educational fruits. Review of Edcuational Research 49: 611-629.

Hill, C., 1982. Radical prose in 17th century England: From Marprelate to the Levellers. Essays in Criticism 32: 95-118.

Hoffman, R.R. and R.P. Honeck, 1980. A peacock looks at its legs: Cognitive science and figurative language. In: R.P. Honeck and R.R. Hoffman (eds.), Cognition and figurative language. Hillsdale, NJ: Erlbaum.

Koscyk, K., 1974. Sprache und Theorie der Massenkommunikation. In: W.A. Koch (ed.), Perspektiven der Linguistik, Vol. II, 40-60. Stuttgart: Kröner.

Linde, C. and W. Labov, 1975. Spatial networks as a site for the study of language and thought. Language 51: 924-939.

Maher, J.H. and H. Sullivan, 1982. Effects of mental imagery and oral and print stimuli on prose learning of intermediate grade children. Educational Communication and Technology Journal 30: $175-183$.

Miller, G.A., 1979. Images and models, similes and metaphors. In: A. Ortony (ed.), Metaphor and thought, 202-250. Cambridge: Cambridge University Press.

Neisser, U., 1976. Cognition and reality. New York: W.H. Freeman.

O'Day, R., 1982. Education and society 1500-1800: The social foundation of education in early modern Britain. London: Longman.

Olson, D.R., 1988. Mind and media: The epistemic functions of literacy. Journal of Communication 38: 27-36.

Ong, W.J., 1958. Ramus, method, and the decay of dialogue. Cambridge, MA: Harvard University Press.

Ong, W.J., 1967a. In the human grain. New York: Macmillan.

Ong, W.J., 1967b. The presence of the word. New Haven, CN: Yale University Press.

Ong, W.J., 1971. Rhetoric, romance, and technology. Ithaca, NY: Cornell University press.

Ong, W.J., 1982. Orality and literacy. The technologizing of the word. London: Methuen.

Paivio, A., 1979. Images and verbal processes. Hillsdale, NJ: Erlbaum.

Paivio, A., 1986. Mental representations. A dual coding approach. New York: Oxford University Press.

Shepard, L., 1973. The history of street literature. Newton Abbott: David and Charles.

Siebert, F.S., 1965. Freedom of the press in England 1476-1776: The rise and decline of government control. Urbana, IL: University of Illinois Press.

Stone, L., 1964. The educational revolution in England, 1560-1640. Past and Present 28: 41-80. 
Stone, L., 1969. Literacy and education in England 1640-1900. Past and Present 42: 69-139.

The Thomason Tracts 1640-1661. Microfilm edition of the Thomason Tracts of the British Library, 1981. Ann Arbor, MI: University Microfilms International.

Traue, J.E., 1978. 'A sort of appeal to the people': A recent acquisition of English broadsides and broadsheets 1641-1714. Turnbull Library Record 11: 104-111.

Wagener, M. and K.F. Wender, 1985. Spatial representations and inference processes in memory for prose. In: G. Rickheit and H. Strohner (eds.), Inferences in text processing, 115-136. Amsterdam: North Holland.

Wedgwood, C.V., 1983. The trial of Charles I. Harmondsworth: Penguin.

Wrightson, K., 1984. English society 1580-1680. London: Hutchinson.

Yates, F.A., 1966. The art of memory. London: Routledge and Kegan Paul. 